\title{
Fluid pressure evolution during the earthquake cycle controlled by fluid flow and pressure solution crack sealing
}

\author{
Jean-Pierre Gratier ${ }^{1}$, Pascal Favreau ${ }^{1}$, François Renard ${ }^{1}$, and Eric Pili ${ }^{2}$ \\ ${ }^{1}$ LGIT, CNRS-Université Joseph Fourier, BP 53X, 38041 Grenoble 38041, France \\ ${ }^{2}$ DASE, CEA, BP 12, 91680 Bruyères le Châtel 91680, France
}

(Received February 8, 2002; Revised September 18, 2002; Accepted September 19, 2002)

\begin{abstract}
Recent studies of active Californian faults allow us to investigate the mechanisms of fluid flow and crack sealing along faults and to model fluid pressure evolution during earthquake cycles. The model is first based on the observation that fluids flow from depth along active faults (stables isotopes and traces elements analyses). The model is also based on the study of mechanisms of deformation of rocks near and within active faults at depth. Sampling was performed in faults that have been recently uplifted. Studies on thin sections of rocks produce evidence of the mechanisms of crack sealing and compaction of fractured zones as transient processes after each earthquake. We found that pressure solution creep and crack sealing are likely to control deformation and permeability change during inter-seismic period. Crack sealing and compaction processes are modeled to give the kinetics of these processes. Then numerical modeling of fluid pressure and transfer around active faults have been performed by integrating slow changes in permeability by crack sealing, gouge compaction and fluid flow from depth. This modeling shows that location and evolution of fluid overpressure varies during the inter-seismic period depending on the heterogeneity of the faults (nature of minerals and fluids, spacing between micro-fractures, thermodynamic and kinetics parameters).
\end{abstract}

\section{Introduction}

The presence of fluid in active fault at depth is evidenced by various types of data: geophysical data (e.g. magnetotelluric field studies), geochemical data (e.g. stable isotopes analyses in mineral deposits), geological data (e.g. fluid inclusion studies in minerals of sealed fractures) and many other ones (Sibson, 1981). Some of these studies (as fluid inclusion density measurements) also show that fluid pressure can evolve during time in relation to fracturing and sealing processes. Several models pertaining to earthquake cycles imply intermittent fluid flow through fault zones. Progressive increase in fluid pressure is assumed during the inter-seismic period, from near hydrostatic values (after an earthquake) to near lithostatic values (before an earthquake). Such an evolution of fluid pressure near active faults is a crucial parameter that may play an important role in the mechanisms leading to earthquakes. To achieve such elevated pressures, geodynamic processes (such as gouge compaction, fluid flow from depth), as well as changes in permeability are required. Various models have been proposed to evaluate the change of fluid pressure associated with seismic cycle such as flow of fluid from depth at high pressure (Sibson, 1981; Byerlee, 1990; Rice, 1992), or compaction within fault gouges (Sleep and Blanpied, 1994). In these models rapid sealing is postulated leading to a fast decrease in the permeability of the country rock around the fault.

Recent studies of active Californian faults bring comple-

Copy right (C) The Society of Geomagnetism and Earth, Planetary and Space Sciences (SGEPSS); The Seismological Society of Japan; The Volcanological Society of Japan; The Geodetic Society of Japan; The Japanese Society for Planetary Sciences. mentary data for such a modeling and allow us to integrate both the slow permeability change and the fluid flow in the modeling of fluid transfer along active fault during interseismic period. The model is first based on the recognition of source and pathway of fluids that flow from depth along active faults (stable isotopes and trace elements analyses). The model is also based on the study of mechanisms of deformation of rocks near and within active faults at depth. Sampling was performed in faults that have been recently uplifted. Studies on thin sections of rocks gave evidence of the mechanisms of crack sealing and compaction of fractured zones mostly by pressure solution at depth after each earthquake (Figs. 1 and 2). This study presents models of the crack sealing and compaction that give the kinetics of these processes and consequently allow us to model episodic fluid transfer along active fault during the inter-seismic period.

\section{Source and Pathway of the Fluid along Califor- nian Faults}

The model is first based on the observation that fluids flow from depth along active faults. This was evidenced by isotope studies (Kennedy et al., 1997; Pili et al., 1998, 2002a). For example, in this last study, $\mathrm{C}$ and $\mathrm{O}$ isotope analyses of carbonates from gouges, veins fillings and their host rocks form a consistent trend indicating percolation of external fluid from depth. Ranking in terms of increasing isotope depletion, and thus increasing deep-fluid signature stand: the host rocks, the vein filling and the gouges (maximum deepfluid signature). Mantle signature, revealed by (Kennedy et al., 1997), from ${ }^{3} \mathrm{He} /{ }^{4} \mathrm{He}$ ratios studies, are dispersed in the 


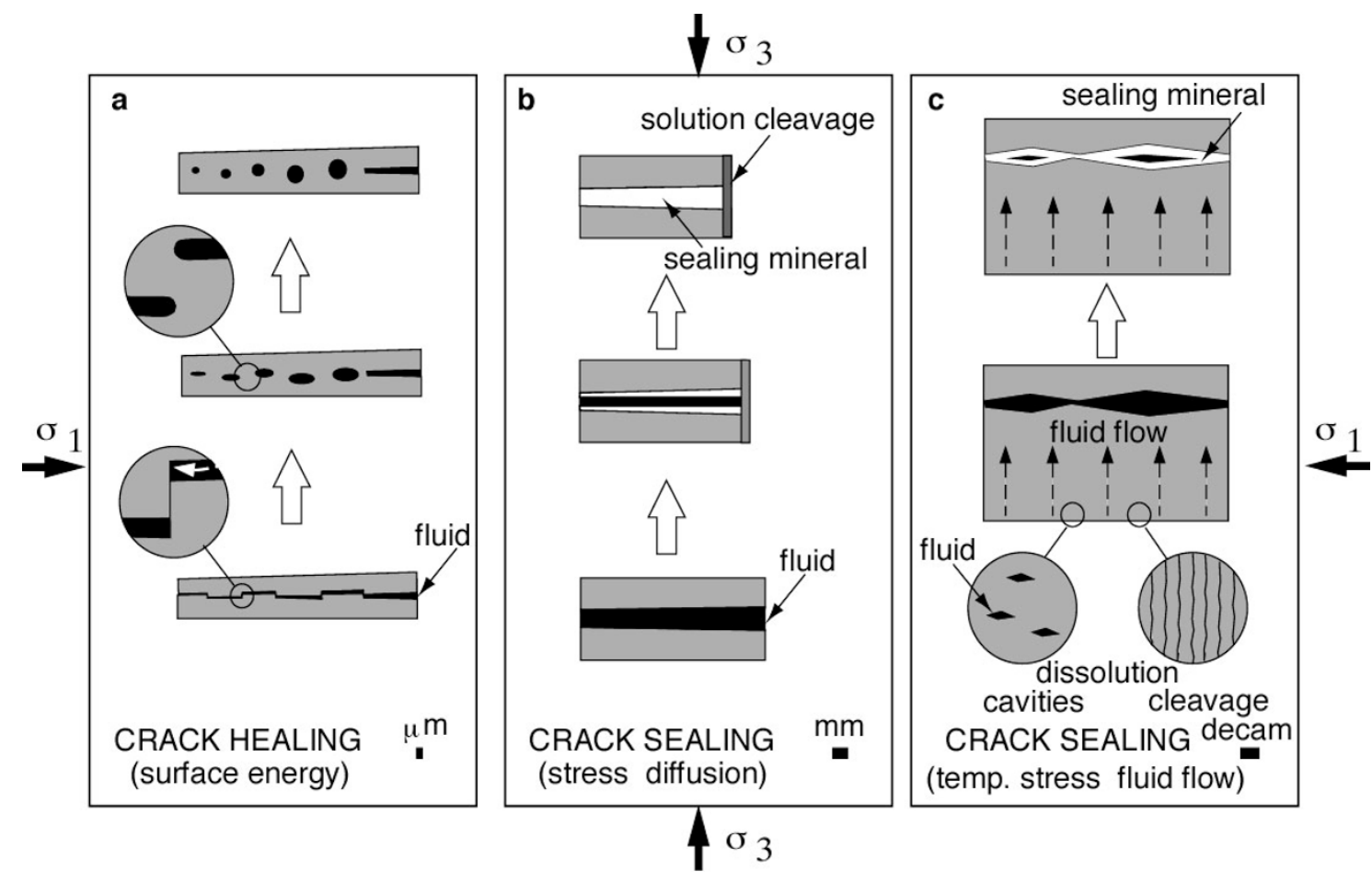

Fig. 1. Various mechanisms of cracks sealing: (a) micro-crack self-healing; (b) pressure solution diffusive mass transfer, (c) precipitation from fluid at regional scale. Evolution with time from bottom to top (arrows). In cross sections perpendicular to the fractures, the host rocks are gray colored, the black areas are the fluid phase, the white areas are the precipitated minerals. After Gratier et al. (2002).

present day groundwater associated with the San Andreas system. Such mantle helium signatures have also been evidenced in fluid inclusions within precipitated minerals sealing gouges and veins (Pili et al., 1998, 2002a). These studies revealed the pathway of the fluids localized along the fault. From these results, fault zones at a given depth $(2-5 \mathrm{~km})$ appear to have been infiltrated during deformation by fluids of deeper origin dominated by crustal water with mantle contribution. Meteoric water does not represent a significant contribution. Such isotopic signatures indicate that the fluids, which were not in equilibrium with the host rocks, flow through the entire gouge and the vein system. However, to explain their more marked deep-fluid signature, the gouges must have been infiltrated several times (in connection with several earthquakes) whereas veins were mostly open and sealed once (in connection with a single earthquake). This is compatible with observation (see below) that part of the mineral matter of the gouges and most of the vein filling mineral material are actually derived from the country rocks (Gratier et al., 2002). From time to time, probably after earthquake occurrences, gouges and veins are connected together, then, during inter-seismic period, crack sealing occurs by input of mineral mostly removed from nearby country rocks by pressure solution stress-driven processes (see details below).

The mechanism of fluid flow has also been deciphered by trace element analyses and structural observations (Pili et al., 2002b): the trace elements (including REE) are enriched in host rocks and depleted in veins and gouges. We suggested that trace elements in fluid are scavenged by complexation with organic matter in the host rocks resulting from two effects. The effect of the flow of external fluid is the major effect. However, as significant volume decrease of the host rocks is observed around the faults, such a volume decrease, associated with pressure solution compaction (see Fig. 2(b)), contribute to the passive concentration of the trace elements. Consequently, results of both stable isotope and trace element analyses are interpreted as bringing evidence for a mixed "focused-pervasive" fluid flow model. The fluid mainly flows within veins and deformation zones, but simultaneously part of the fluid flows pervasively in the host rocks where trace elements are scavenged.

\section{Observation of Natural Crack Sealing and Com- paction Processes Near Active Fault}

Samples were collected near active faults and studied with great care to deal only the structures clearly related with the active displacement of these faults at depth prior to their uplift. Samples were collected from three faults in California: Little Pine, San Gabriel and Mother Lode faults (Gratier et al., 2002), the sampled sites corresponding to different depths of crack-sealing from 2 to $5 \mathrm{~km}$ and up to $7-10 \mathrm{~km}$, respectively. The main characteristics of the observed natural structures can be summarized in conceptual models based on specific observation around the Californian faults (thin sections are shown in Fig. 2). Fluid inclusion networks in the mineral precipitates reflect the presence of fluid during the sealing of the cracks. Evidence of crack self-healing (driven by the lowering of surface energy) can be seen in minerals but is restricted to very thin fractures of several microns width (Fig. 1(a)). Most of the veins related to active faults are sealed with precipitation of mineral. Within the gouges, the growth of some phyllosilicate minerals is indicative of metamorphic reactions with external fluids. So clearly, the process of filling some gouges and veins fill- 

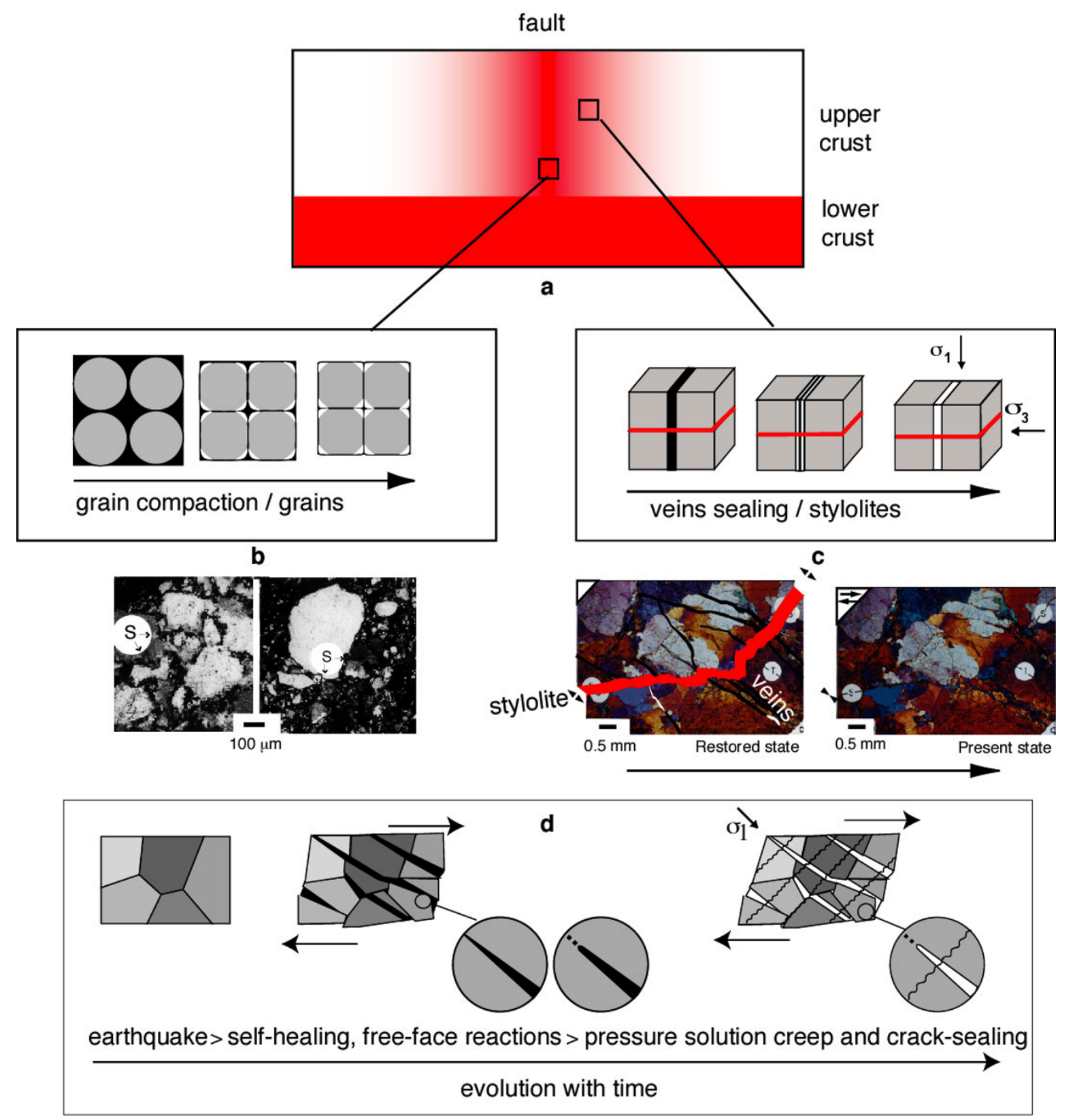

Fig. 2. Grain compaction in gouge and crack sealing around faults: (a) location of these mechanisms in crustal cross section (the red area is the volume of rock wets by fluids flowing from depth); (b) compaction model geometry (model and natural observation); (c) crack sealing model geometry (model and natural observation); (d) progressive sealing process in inter-seismic period (the host rock is gray colored, the black part is the fluid phase, the white part is the precipitated mineral): evolution of fluid pressure with time is modeled in Fig. 4. Adapted from Gratier et al. (2002) and Pili et al. (2002a).

ing are related to reactions with fluids coming from depth. However, most of the mineral precipitates in veins (quartz, calcite) are removed from nearby solution cleavage and stylolites in country rocks. This can be demonstrated both by geometric arguments (veins interrupted against solution surface) and by chemical arguments (as the same mineral is dissolved in solution cleavage and is re-precipitated in veins, Figs. 1(b) and 2(c)). With reference to other markers of the deformation, as micro-faults, dissolution interfaces are oriented perpendicular to $\sigma_{1}$ and fractures are opened perpendicular to $\sigma_{3}$. Such orientations are in agreement with a stress gradient driven mass transfer, namely pressure solution (Fig. 2(c)). The size of the closed system (the size for which the dissolved volume is equal to the precipitation volume) may vary from millimeters (Fig. 1(b)) to hundred me- ters (Fig. 1(c)-right). This last case (Fig. 1(c)) is supported by the calculation of regional volume decrease, associated with penetrative solution cleavage: up to $-30 \%$, over tens of meters around the faults deduced from mass balance between the dissolution volume (evaluated both from microfolded veins and comparative chemical analysis) and the reprecipitation volume (Gratier et al., 2002). Therefore, we consider that pressure solution deposition is the main mechanism that controls crack sealing kinetics around active faults. In parallel, systematic compaction occurred in the gouges after the seismic cataclastic process, mostly also by pressure solution (Fig. 2(b)). This is compatible with the "focusedpervasive" fluid flow model deduced from geochemical studies, with rock deformation being mostly controlled by local diffusive mass transfer (pressure solution rate can be the lim- 
iting step in both models of Figs. 1(b) and 1(c)). Rheological parameters of the rocks may be estimated directly from finite deformation analysis (Gratier et al., 2002). When considering pressure solution creep as a Newtonian viscous flow for simplicity (Raj, 1982), the strain-rate is proportional to the shear stress and inversely proportional to the viscosity coefficient. Constant strain-rate is derived from true finite strain (30\% shortening). Assuming a total duration of $4 \mathrm{My}$ (strainrate $\left.=2.510^{-15} \mathrm{~s}^{-1}\right)$ and a mean differential stress value of $20 \mathrm{MPa}$ (Gratier, 1987) the "mean viscosity coefficient" is estimated to be $8 \times 10^{21} \mathrm{~Pa}$.s. This is a maximum value since pressure solution creep may be limited to a short period after each earthquake (see discussion below).

Quartz and calcite are the main minerals of which components are mobile. They are removed from the stylolites and solution cleavage and re-precipitated in veins and pores. However, the relative mobility of quartz and calcite components clearly changes with depth. At shallow depth, calcite component is more mobile than quartz component while the reverse is true at greater depth. This variation is related to two converging effects:

(i) the solubility of quartz and calcite varies inversely with increasing temperature (normal and reverse relation for quartz and calcite, respectively),

(ii) at low temperature, the kinetics of quartz dissolution is very slow and this prevent significant pressure solution process (Oelkers et al., 1996; Renard et al., 1997).

Experimental data (Brantley et al., 1990) show that the crack-healing process may be rather fast (days, weeks) as reaction occurs on free faces. On the contrary, the kinetics of crack sealing due to pressure solution is always very slow. This is mostly due to the slow rate of diffusive flux out of the stressed solution interface, which is the most often limiting step of the process, at depth. The kinetics of the sealing process associated with fluid flow may be either fast or slow depending on the limiting step (Fig. 1(c)). This kinetics is very slow if the diffusive mass transfer out of intergranular fluid under stress is the limiting step (Fig. 1(c)right). Kinetics could be fast in case of dissolution on free faces around pores or voids (Fig. 1(c)-left).

According to the observation of natural structures, the following successive crack sealing processes are expected to occur in active fault zones during inter-seismic periods (see sketch, Fig. 2(d)). Initially, an earthquake increases the overall permeability and reduces fluid pressures to levels approaching hydrostatic values within the fault zone. The first stages of fluid/rock interactions can be characterized by rapid kinetics depending on the reactions taking place on free faces. Self-healing of the fractured mineral and some metamorphic reactions are relevant to this stage. However, in the studied examples, these processes do not play a major role in the sealing of the open cracks. The second stage, involving pressure solution along stylolites and crack sealing, with diffusion through an intergranular fluid under stress, is found to be much more common. Pressure solution deformation (Fig. 2(c)) and compaction process (Fig. 2(b)) accommodated the interseismic stress. In parallel, decrease in pore pressure after each earthquake increases the effective stress between the grains promoting the compaction of the gouge (Fig. 2(b)). The progressive dissolution of the grains at their contacts decreases the effective stress imposed on the matrix, progressively decreasing the deformation and compactionrate. We consider that such slow stress-driven pressure solution crack sealing and compaction processes control the change of porosity and permeability at depth after an earthquake.

\section{Crack Sealing and Compaction Modeling around Fault}

The modeling of crack sealing and compaction processes implies data both on the kinetics of mass transfer (solid-fluid reactions and diffusion along an intergranular fluid between stressed crystals) and on the geometry of the path of mass transfer (Gratier et al., 1999; Renard et al., 2000). Kinetic parameters are derived from previous experiments (Rutter, 1976; Gratier and Guiguet, 1986; Spiers and Schutjens, 1990). The geometry of the mass transfer path evolves with time and is derived from the observation of thin sections of rock sampled near and within the active faults. Two schematic variations have been considered:

(i) for grain compaction modeling within the gouges (Fig. 2(b)), pressure solution occurs by dissolution at grain contacts and precipitation of the dissolved matter in the pore space. By this mechanism, grains indent each other and the overall porosity decreases,

(ii) for crack-seal and creep modeling around the faults, mass transfer takes place between dissolution surfaces (i.e. stylolites), perpendicular to the maximum compressive stress direction and precipitation occurs in open cracks (Fig. 2(c)).

Relations between the displacement rate of an interface of dissolution $\Delta l / \Delta t$ and various pressure solution parameters are derived from theoretical creep laws (Raj, 1982; Rutter, 1983). It is assumed that the limiting process is either (1) the the reaction rate for dissolution/deposition or (2) the diffusion rate of mass transfer:

$$
\begin{aligned}
\Delta l / \Delta t & =\frac{A k c \Delta \mu}{R T} \\
\Delta l / \Delta t & =\frac{B D c w \Delta \mu}{R T d^{2}}
\end{aligned}
$$

where $\Delta \mu$ is the difference of chemical potential between dissolution and deposition surfaces (Shimizu, 1995) which is the driving forces of the mass transfer due to the difference of normal stresses between dissolution and deposition surfaces, $k c$ is the reaction rate (meter per seconde for a chemical potential difference of $R T$ per mole (Raj, 1982)), $R$ is the gas constant, $T$ is the temperature, $c$ is the solubility of solid in solution (solid/fluid volume ratio), $w$ is the width of diffusive transport path, $D$ is the diffusion coefficient for the rate limiting species, $d$ is the diameter of the surface of dissolution under stress, $A$ and $B$ are numerical coefficients depending on the geometry of the structure. The results of the calculations are given in Fig. 3 for crack sealing of calcite and quartz-rich rocks and for a gouge of quartz-rich rock (Renard et al., 2000). Two time scales emerge from our calculations: pervasive pressure solution at granular scale on the gouge is much faster than pressure solution along stylolites and precipitation in the veins. So, following this model, compaction of the gouge must be relatively fast, however, porosity (and permeability) around the fault is maintained 

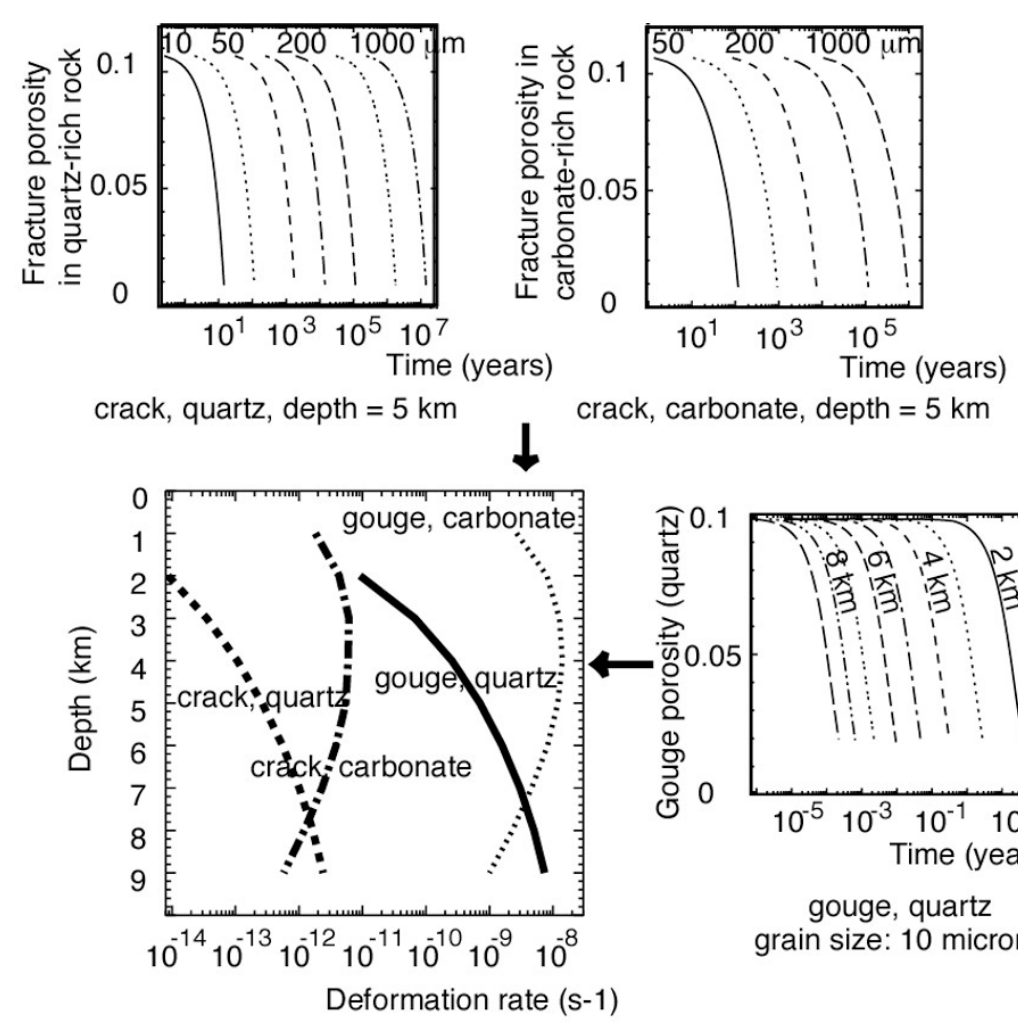

crack, carbonate, depth $=5 \mathrm{~km}$

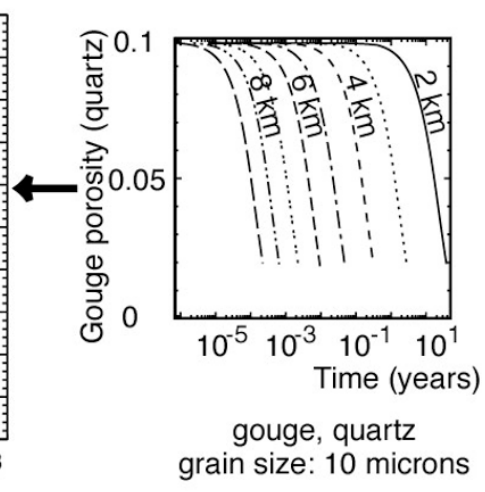

Fig. 3. Kinetics of gouge compaction and crack sealing calculated from pressure solution modeling when using the geometry of the deformed structure given in Fig. 2 and deformation rate versus depth relations. Adapted from Renard et al. (2000). Top: time scale of the crack sealing process for quartz (left) and calcite (right) at geological conditions corresponding to a depth of $5 \mathrm{~km}$ (geometric model Fig. 2(c)). The time scale of sealing depends on the mean distance between the cracks: very fast (10 years) for dense arrays of small cracks to very long ( 10 million years) for a loose arrays of wider cracks. Bottom right: time scale of gouge compaction process for quartz at different depths (geometric model Fig. 2(b)), showing that with increasing depth the compaction-rates increase up to four orders of magnitude. This can be related to the increasing solubility of quartz with temperature. Bottom left: The creep rates of crack sealing and gouge pressure solution depend on depth and on the mineralogy of the rocks. For both fracture sealing-rate and gouge compaction-rate, there is a depth at which the deformation rates curves of quartz rich and calcite rich rocks cross. This can be understood as the solubility of calcite decreases with depth whereas the solubility of quartz increases.

for a rather long time.

Mass transfer by pressure solution from stylolites to veins (crack sealing process) may also be expressed as a creep law. Deformation rates change with depth in a different manner for quartz-rich and carbonate-rich rocks due to the reverse dependence of the solubility of these two minerals with temperature (Fig. 3). The equivalent "regional" viscosity calculated for fractured carbonate-rich rocks, at $2 \mathrm{~km}$, is $6 \times 10^{18}$ Pa.s. This value may be compared with the value found from the study of natural deformation. For example, analysis of deformed carbonates rocks near Little Pine Fault give value of $8 \times 10^{21}$ Pa.s (see above). It may also be compared with viscosity value of sedimentary cover deduced from the comparison between numerical modeling of the Ventura basin and its natural structures: "mean viscosity" ranges between $10^{20}$ and $10^{21}$ Pa.s (Nino et al., 1998). There are several possibilities to explain this difference. For our modeling, one of them is the uncertainty on the spacing between the cracks, another is related to the uncertainty on kinetic parameters estimated from experiments. For the values deduced from natural deformation, however, the duration of the deformation represents the main uncertainty. The two values of natural viscosity have been estimated when considering the total duration of the deformation (4 My). It is possible that pressure solution creep occurs chiefly during a limited period after each earthquake. Triggered by fracture development, the kinetics of pressure solution shows exponential decrease rates (Fig. 3). These uncertainties could explain the difference of viscosity values when comparing the relatively fast calculated post-seismic creep rate and the mean deformation-rate for tectonic period. Moreover, the soon after earthquake creep rate might itself include two time scales: very fast strain-rate along gouges (months-years) and slower strain-rates associated with crack sealing (several years to centuries). This is compatible with geodetic measurements, which show large post-seismic deformation of ground surface in California (Donnelan and Lyzenga, 1998). Therefore, pressure solution creep and crack sealing are likely to be interpreted as transient processes activated by earthquake (this is due to the crucial effect of the micro-fracturing process which reduce the distance of diffusive mass transfer along stylolites, Fig. 2(c)).

\section{Numerical Modeling of Fluid Transfer along Ac- tive Fault}

Assuming that the slower process limits the overall porosity of the fault zone, the change in porosity and permeability are modeled only by the crack sealing of veins in country rocks. In such cases, as seen in Fig. 3, porosity variation curves are almost linear, from $10 \%$ to $0 \%$, indicating an ex- 
ponential decrease of the porosity with time. Such a simplified relation was used as porosity decrease model in the numerical modeling of fluid transfer presented below.

The basis of the numerical model is relatively simple (Gratier et al., 2002). A post seismic fluid pressure decrease, down to the hydrostatic pressure, is assumed in a narrow volume around the fault from the base of the seismic crust to the top of the free topographic surface. In the lower crust the fluid remains at a constant lithostatic pressure. Consequently after each earthquake as fluid pressure is assumed to drop to hydrostatic pressure, the fluid pressure in the fault tends to increase due to the mass transfer from this lower level to the fault zone (Rice, 1992). The difference between our model and the Rice model is that instead of having instantaneous sealing around the fault, we assume that the permeability within and around the faults slowly decreases with time. This aspect of progressive change in porosity could be matched with the Sleep and Blanpied (1994)'s model, however in their approach this change of porosity is restricted to the gouge which is a closed system due to rapid sealing of the rock around the fault. Consequently, in our model there are two types of processes that may increase the fluid pressure the inflow of fluid from depth and the progressive, heterogeneous and slow change in porosity and permeability by crack sealing (because, see Fig. 3, the compaction of the gouge is relatively fast compared to the crack sealing).

Let us define the two directions of the 2D model of fluid flow: $x$ is perpendicular to the fault and $z$ is the depth, $t$ is the time. The hypotheses of the model are the following: porosity and permeability reduction by crack sealing, fluid mass conservation, Darcy's law, simplified poroelastic body (constant total stress), small perturbation approximation and the pressure is always lower than the lithostatic pressure. We derive an equation for the pressure increase $p$ in the crust surrounding the fault, for all $x, z, t$ :

$$
\begin{aligned}
& \phi_{m} C(\partial p / \partial t)+\left(\partial \phi_{m} / \partial t\right) \\
& \quad=(\partial / \partial x+\partial / \partial z)\left(K_{x} \partial p / \partial x+K_{z} \partial p / \partial z\right) ; \\
& p<P_{\text {litho }}-P_{\text {hydro }}=-g\left(\rho_{\text {litho }}-\rho_{m}\right) z .
\end{aligned}
$$

In this equation $\phi_{m}$ is the porosity imposed by the crack sealing. $C\left(\mathrm{~Pa}^{-1}\right)$ is the compressibility of the matrix and the fluid at constant total stress. $K_{x}$ and $K_{z}\left(\mathrm{~Pa}^{-1} \mathrm{~m}^{2} \mathrm{~s}^{-1}\right)$ are permeability related coefficients. $P_{\text {litho }}$ and $P_{\text {hydro }}$ are the lithostatic and hydrostatic pressure. $g$ is the gravity, $\rho_{m}$ and $\rho_{\text {litho }}$ are the densities of the fluid and the rock.

Following the natural observations and the crack sealing modeling, we define:

$$
\phi_{m}(x, z, t)=\phi_{o} e^{-x / L} e^{-t / \tau(z)} .
$$

$\phi_{o}$ is the maximal initial porosity, $L$ is the characteristic distance along the $x$ axis, for the exponential decrease of the porosity after each earthquake (distance for which the maximum porosity $\phi_{o}$ along the fault is divided by 2.72). $\tau(z)$ is the characteristic time of the sealing process (time during which the initial porosity is divided by 2.72). Following Lockner and Evans (1995), we assume that the permeability decreases in time as the cube of the porosity, therefore we define:

$$
K_{x}(x, z, t)=\left(k_{0} /\left(\rho_{m} g\right)\right) e^{-x / L} e^{-3 t / \tau(z)}
$$

and $K_{z}=100 K_{x}$ (Rice, 1992) (a vertical strong anisotropy is suggested by the observations). $k_{0}\left(\mathrm{~ms}^{-1}\right)$ is the "kinematic" permeability at the center of the fault just after the earthquake.

Finally, condition $p<P_{\text {litho }}-P_{\text {hydro }}$ corresponds to a cutoff due to local hydraulic fracturing of the crust.

The shape of $\tau(z)$ is derived from a modeled stratified crust deduced from a synthesis of the Californian examples. A simplified variation with depth is used, assuming that the rate of crack sealing is controlled by calcite (increasing rate from 0 to $2-3 \mathrm{~km}$ ), by quartz (increasing rate from 5 to 10 $\mathrm{km}$ ), and by an intermediate behavior (decreasing rate from 3 to $5 \mathrm{~km}$ ) (reference to Fig. 3). Due to the uncertainty on the parameters of the calculation the same $\tau(z)$ profile has been used with three different orders of magnitude for the $\tau$ values $(i, j, k)$, with the following slowest $(5 \mathrm{~km})$ and fastest values $(2-3 \mathrm{~km})$ (i): $10000>\tau_{i}>700$; (ii): $1000>\tau_{j}>70$; (iii): $100000>\tau_{k}>7000$ years. These values are strongly dependent on the geometry of the path of mass transfer (Fig. 2). For example, the medium values of the profile $\left(\tau_{j}\right)$ are obtained with a spacing between fractures which is of the order of magnitude of $100 \mu \mathrm{m}$ (with crack width of $6 \mu \mathrm{m})$. Shifting the $\tau$ values by one order of magnitude higher $\left(\tau_{k}\right)$ or lower $\left(\tau_{i}\right)$ corresponds to spacing of 200 or $50 \mu \mathrm{m}$, respectively (with crack widths of 12 or $3 \mu \mathrm{m}$ respectively). From the observations of natural crack sealing, a mean spacing of 100 to $200 \mu \mathrm{m}$ seems realistic (Fig. 2).

Several calculations have been performed with an explicit finite difference method. $\phi_{o}$ is taken as equal to $10 \%$. $L=100 \mathrm{~m}$. The boundary conditions for fluid pressure are hydrostatic pressure at the surface $(z=0)$, lithostatic pressure below the fault zone at the brittle/plastic transition $(z=-10 \mathrm{~km})$ and hydrostatic pressure at horizontal distance of $2 \mathrm{~km}$ of the fault $(x=2 \mathrm{~km})$. Various calculations have been done with two values of the initial kinematic permeability coefficients: $k_{0}=10^{-9} \mathrm{~ms}^{-1}$ and $k_{0}=10^{-8} \mathrm{~ms}^{-1}$ which correspond respectively to geometric permeabilities: $k_{0} \eta /\left(\rho_{m} g\right)=5 \cdot 10^{-18} \mathrm{~m}^{2}$ and $5.10^{-17} \mathrm{~m}^{2}$ with a fluid viscosity $\eta=1.510^{-4} \mathrm{Pas}\left(\right.$ at $\left.160^{\circ} \mathrm{C}\right)$. We take $C=10^{-9} \mathrm{~Pa}^{-1}$, $g=10 \mathrm{~ms}^{-2}, \rho_{m}=800 \mathrm{kgm}^{-3}$ and $\left(\rho_{\text {litho }}=2800 \mathrm{kgm}^{-3}\right.$. Results are given in Fig. 4 that show pressure distribution in cross sections perpendicular to the fault (Gratier et al., 2002). The effects of the two competing processes (influx from depth and sealing-rate around the fault) are observed. Just after an earthquake, overpressure always develops at the bottom of the fault, due to the inflow of fluid from depth. All the models show this effect (Fig. 4), leading to a very localized high pressure zone (up to lithostatic values) that develops quickly (years) after an earthquake. With the lowest sealing-rates (Fig. 4(a)) overpressure slowly extends to the entire fault zone. After several hundred years, normalized overpressure $O_{v p}=p /\left(P_{\text {litho }}-P_{\text {hydro }}\right)$ reaches values about 0.6 in the median part of the fault zone. It could take thousand years or more to develop lithostatic pressure all along the depth of the vertical fault (we did not performed the computation longer because of the time calculation). With the fastest sealing-rate (Fig. 4(b)) another overpressure zone develops in the upper part of the seismic zone (between 2 and $5 \mathrm{~km}$ depth) due to the fast sealing-rate of calcite after only 

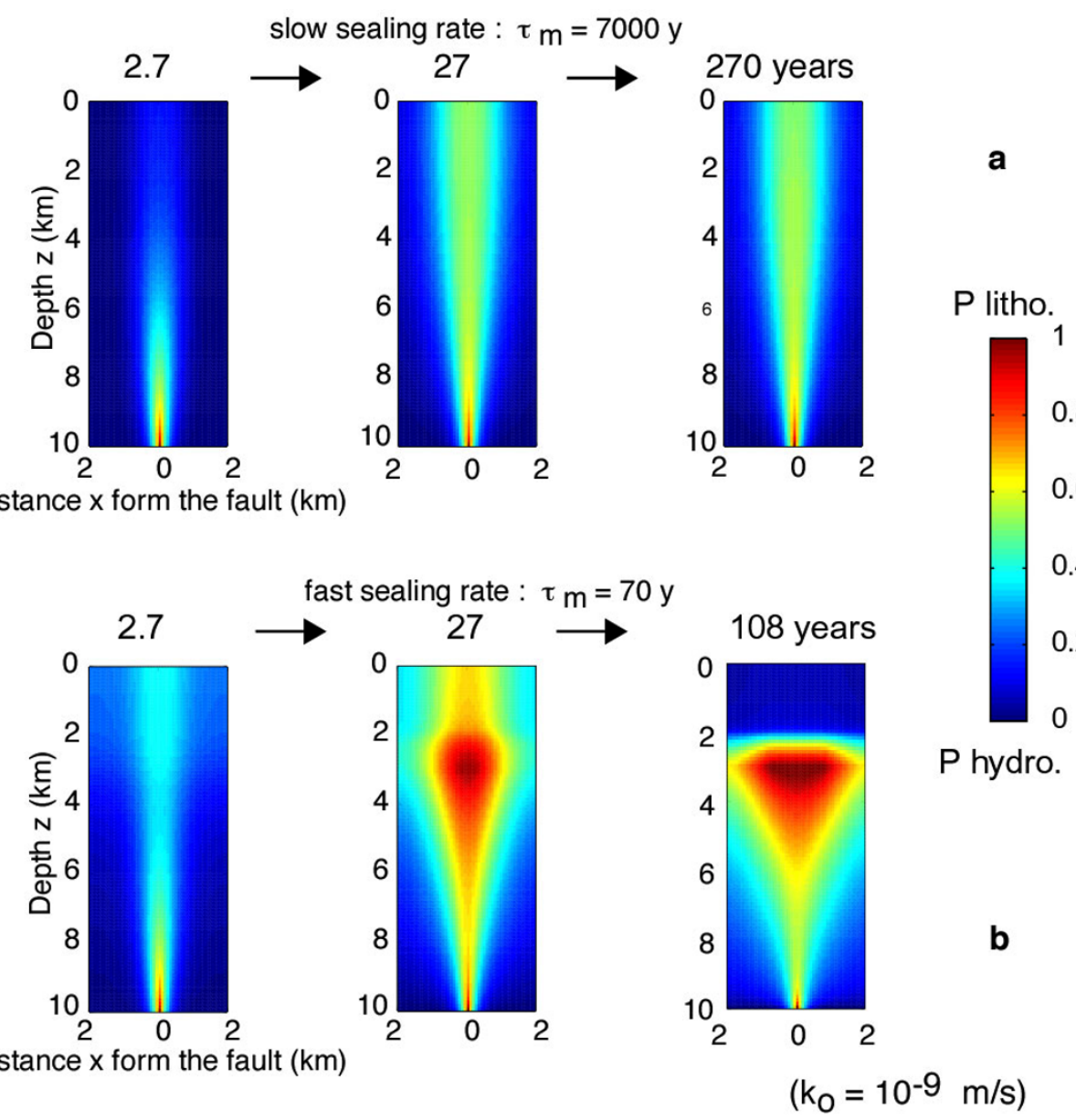

a

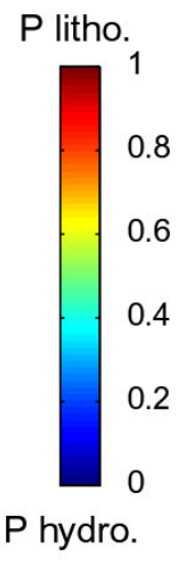

$b$

Fig. 4. Evolution of fluid pressure along active fault, from hydrostatic (blue) to lithostatic (red) pressure, during the inter-seismic period: effect of the kinetics of crack sealing. $\tau(z)$ is the characteristic time (time during which the initial porosity is divided by 2.72 ). $\tau(z)$ vary with depth, $\tau_{m}$ being the value at $2-3 \mathrm{~km}$ in depth. $k_{o}$ is the initial permeability coefficient. Adapted from (Gratier et al., 2002).

several decades. Local overpressure also develops at $3 \mathrm{~km}$ depth with medium sealing-rate, but only after several hundred years. Finally, very tenuous overpressure is noted in the same zone after several hundred years even with the slowest sealing-rate. With high sealing-rate values, the effect of this upper overpressure zone is so strong that, after hundred years, it prevents the fluid to flow out of the crust toward the earth surface (Fig. 4(b)). With high sealing-rate, the high flow rate during the first hundred years is related to both inflow from depth and upward fluid expulsion due to the fast compaction.

Effect of the initial permeability values has been tested. Increase in permeability values facilitates the flow-through process along the fault and so amplifies the development of overpressure at the bottom of the seismic crust and progressively through the faults. This effect of the initial permeability is especially efficient when the sealing-rate is low. In this case, change of one order of magnitude of the permeability values leads to change of one order of magnitude of the flow rate values. However, with high or medium sealing-rate the initial permeability effect is more complex. For example, in the case of medium sealing-rate, the model with the highest permeability develops the highest overpressure during the first decades, however, after several hundred years the effect of initial permeability is not so significant.
The modeling also gives an amount of magnitude of the fluid flow from depth (Gratier et al., 2002) which is not found to be as high as previously thought when assuming that all the mineral sealing of the fractures comes from depth (Fyfe et al., 1978). Fluid inflow from depth wets the fault after each earthquake but crack sealing occurs during the interseismic period mostly by locally derived stress-driven mass transfer.

Assuming that the zone of progressive over-pressuring along faults is likely to be the area of earthquake nucleation, the study evidences the effect of the heterogeneity of the faults (mostly the difference in nature and fracturing of rocks) on the location of earthquakes. The kinetics of crack sealing varies along the fault depending on variation of the nature of minerals and fluids, spacing between microfractures, and thermodynamic and kinetic parameters.

\section{Conclusion}

Stable isotopes and trace elements analyses gave evidence of both the origin and the pathway and mechanism of fluid flow. A mixed focused-pervasive fluid flow model is proposed, with fluids coming from depth. The fluids mainly flow within veins and deformation zones, but part of the fluid flow simultaneously occurs pervasively in host rocks.

After each earthquake, crack sealing is mostly controlled 
by pressure solution with mass transfer at local closed system either at grain scale (compaction of gouge) or between solution surface and veins (crack sealing around the gouge).

The kinetics of natural crack sealing and compaction depends on the nature of minerals and fluids, on the geometry of the path of diffusive mass transfer (spacing between micro-fractures), on thermodynamic parameters (stress, pressure and temperature... ) and on kinetic parameters (solid fluid reaction kinetics and diffusion coefficients).

Micro-fractures development increases the pressure solution creep and crack sealing kinetics, by reducing the diffusive mass transfer distance along an intergranular fluid between stressed solids (which is the rate limiting effect). Therefore, these processes are likely to be interpreted as transient processes, activated by earthquakes. Triggered by fracture development, the kinetics of pressure solution shows exponential decrease rates. In the future, it would be interesting to test if such transient creep processes may be accurately monitored by geodetic measurements.

Models of crack sealing reveal that compaction in gouge must be rather fast compared to the crack sealing which is always very slow. Consequently, fluid flow must occur around the gouge in fractured host rocks for a long time after an earthquake.

Numerical modeling of episodic fluid transfer integrates a combined effect of fluid flow and the progressive (very slow) sealing of the fault based on the crack sealing model.

Results of this modeling show that the kinetics of crack sealing mainly controls the fluid pressure and fluid flux changes (space and time). It also controls the heterogeneous location of the zones of high pressure along the fault.

Due to the contrasted behavior between the main mobile minerals (calcite, quartz) the development of a zone of fast sealing (high pressure) is predicted in the upper crust at some $\mathrm{km}$ of depth where carbonates rocks are found $(2-5 \mathrm{~km}$ in the model). In parallel, the development of another zone of high pressure is also predicted at depth $(10 \mathrm{~km})$, at the transition between upper and lower crust, due to fluid flow from depth. Consequently, the study gives evidence of the effect of the heterogeneity of the faults (fracturing and nature of the rocks) on the location of zones of progressive overpressuring.

These zones of progressive over-pressuring may locate earthquake nucleation, due to the progressive lowering of the strength of the rock. Monitoring such change of fluid pressure at depth, by geophysics or geodetic measurements, would help understanding earthquake mechanisms.

Acknowledgments. Studies in California were supported by the Southern California Earthquake Center and the Institute for Crustal Studies UC Santa Barbara, for the stays of one of us (JPG). All computations presented in this paper were performed at the "Service Commun de Calcul Intensif de l'Observatoire de Grenoble" (SCCI). We thank Tadao Nishiyama and an anonymous reviewer for their very helpful comments and suggestions.

\section{References}

Brantley, S., B. Evans, S. H. Hickman, and D. A. Crerar, Healing of microcracks in quartz: implications for fluid flow, Geology, 18, 136-139, 1990.

Byerlee, J., Friction, overpressure and fault normal compression, Geophys.
Res. Lett., 17, 2109-2112, 1990.

Donnelan, A. and D. A. Lyzenga, GPS observations of fault afterslip and upper crustal deformation following the Northridge earthquake, J. Geophys Res., 103, 21285-21297, 1998.

Fyfe, W. S., N. J. Price, and A. B. Thompson, Fluids in the earth's crust, 383 pp., Elsevier, 1978.

Gratier, J. P., Pressure solution deposition creep and associated chemical differenciation in sedimentary rocks, in Deformation Mechanisms in Sediments and Sedimentary Rocks, edited by M. E. Jones and R. M. F. Preston, J. Geol. Soc. Lond. spec. publ. No. 29, 25-38, 1987.

Gratier, J. P. and R. Guiguet, Experimental pressure solution-deposition on quartz grains: the crucial effect of the nature of the fluid, Journal of Structural Geology, 8, 845-856, 1986.

Gratier, J. P., F. Renard, and P. Labaume, How pressure-solution and fractures interact in the upper crust to make it behave in both a brittle and viscous manner, Journal of Structural Geology, 21, 1189-1197, 1999.

Gratier, J., P. Favreau, and F. Renard, Modeling fluid transfer along Californian faults when integrating pressure solution crack-sealing and compaction processes, J. Geophys. Res., 2002 (in press).

Kennedy, B. M., Y. K. Kharaka, W. C. Evans, A. Ellwood, D. J. DePaolo, J. Thordsen, G. Ambats, and R. H. Mariner, Mantle fluids in the San Andreas fault system, California, Science, 278, 1278-1280, 1997.

Lockner, D. and B. Evans, Densification of quartz powder and reduction of conductivity at $700^{\circ} \mathrm{C}, \mathrm{J}$. Geophys. Res., 100(B7), 13081-13092, 1995.

Nino, F., J. Chéry, and J. P. Gratier, Mechanical modeling of compressional basins: origin and interaction of faults, erosion and subsidence in the Ventura Basin, California, Tectonics, 17, 955-972, 1998.

Oelkers, E. H., P. A. Bjørkum, and W. M. Murphy, A petrographic and computational investigation of quartz cementation and porosity reduction in North Sea sandstones, American Journal of Science, 296, 420-452, 1996.

Pili, E., B. M. Kennedy, M. S. Conrad, and J. P. Gratier, Isotope constraints on the involvement of fluids in the San Andreas Fault, EOS Trans, $A G U$, 79(17), Spring meeting, 1998.

Pili, E., B. M. Kennedy, J. P. Gratier, and M. E. Conrad, Mantle and metamorphic origin of fluids in the veins of the San Andreas fault system deduced from isotopes studies, J. Geophys. Res., 2002a (in preparation).

Pili, E., F. Poitrasson, and J. P. Gratier, Carbon-oxygen and trace elements constraints on how fluids percolate faulted limestone from the San Andreas Fault system: the role of partitioning of fluid sources and pathways, Chemical Geology, 190(1-4), 231-250, 2002b.

Raj, R., Creep in polycrystalline aggregates by matter transport through a liquid phase, J. Geophys. Res., 87, 4731-4739, 1982.

Renard, F., P. Ortoleva, and J. P. Gratier, Pressure solution in sandstones: influence of clays and dependence on temperature and stress, Tectonophys., 280(3-4), 257-266, 1997.

Renard, F., J. P. Gratier, and B. Jamtveit, Kinetics of crack-sealing, intergranular pressure solution and compaction around active faults, Journal Structural Geology, 22, 1395-1407, 2000.

Rice, J. R., Fault stress states, pore pressure distributions, and the weakness of the San Andreas Fault, in Fault Mechanics and Transport Properties in Rocks, edited by B. Evans and T. F. Wong, pp. 475-503, Academic Press, 1992.

Rutter, E. H., The kinetics of rock deformation by pressure solution, Philosophical Transactions of the Royal Society of London, 283, 203-219, 1976.

Rutter, E. H., Pressure solution in nature, theory and experiment, J. Geol. Soc. London, 140, 725-740, 1983.

Shimizu, I., Kinetics of pressure solution creep in quartz: theoretical considerations, Tectonophys., 245, 121-134, 1995.

Sibson, R. H., Fluid flow accompanying faulting: field evidence and models, in Earthquake Prediction: An International Review, edited by D. W. Simpson and P. G. Richards, pp. 593-603, Maurice Ewing Series, AGU 1981.

Sleep, N. H. and M. L. Blanpied, Ductile creep and compaction: a mechanism for transiently increasing fluid pressure in mostly sealed fault zones, Pure and Applied Geophysics, 143(1/2/3), 9-40, 1994.

Spiers, C. J. and P. M. Schutjens, Densification of crystalline aggregates by fluid phase diffusional creep, in Deformation Process in Minerals, Ceramics and Rocks, edited by D. J. Barber and P. G. Meredith, pp. 334 353, Unwin Hyman, 1990.

J.-P. Gratier (e-mail: Jean-Pierre.Gratier@obs.ujf-grenoble.fr), P Favreau, F. Renard, and E. Pili 